\title{
ERK1/2 Signaling Pathway Activated by EGF Promotes Proliferation, Transdifferentiation, and Migration of Cultured Primary Newborn Rat Lung Fibroblasts
}

\author{
Yu Hu, JianHua Fu, XueYan Liu, and XinDong Xue \\ Department of Pediatrics, Shengjing Hospital of China Medical University, 36 Sanhao Street, Shenyang, Liaoning 110004, China \\ Correspondence should be addressed to XinDong Xue; 18940257678@163.com
}

Received 31 May 2020; Accepted 25 August 2020; Published 6 October 2020

Academic Editor: Shoichiro Ono

Copyright ( $2020 \mathrm{Yu} \mathrm{Hu}$ et al. This is an open access article distributed under the Creative Commons Attribution License, which permits unrestricted use, distribution, and reproduction in any medium, provided the original work is properly cited.

Background. Bronchopulmonary dysplasia (BPD) is a common and serious complication in premature infants. Lung fibroblasts (LFs) are present in the extracellular matrix and participate in pulmonary development in response to BPD. The aim of this study was to investigate the effect of extracellular signal-regulated kinase (ERK) on LFs cultured from newborn rats. Material and Methods. Primary LFs were isolated and treated with epidermal growth factor (EGF, $20 \mathrm{ng} / \mathrm{mL}$ ) in the presence or absence of an ERK inhibitor, PD98059 $(10 \mu \mathrm{mol} / \mathrm{L})$. Phosphorylated ERK1/2 (p-ERK1/2) protein levels were determined using immunocytochemistry, western blotting, and real-time reverse transcription quantitative (RT-q)PCR. LF proliferation was examined by flow cytometry and a cell counting kit- 8 assay. LF transdifferentiation was examined by protein and mRNA expression of $\alpha$-smooth muscle actin ( $\alpha$-SMA) by immunocytochemistry, western blotting, and RT-qPCR. LF migration was examined by the transwell method. Results. Phosphorylated ERK1/2, which was activated by EGF, promoted LF proliferation by accelerating cell-cycle progression from the G1 to S phase. After treatment with PD98059, the expression of p-ERK1/2 in LFs, cellular proliferation, and the percentage of cells in S phase were significantly decreased. Phosphorylated ERK1/2 also promoted the differentiation of LFs into myofibroblasts through increased $\alpha$-SMA synthesis and migration. Conclusion. The activation of ERK promotes proliferation, transdifferentiation, and migration of lung fibroblasts from newborn rats.

\section{Introduction}

Bronchopulmonary dysplasia (BPD) is a serious chronic pulmonary complication often seen in preterm neonates experiencing long-term ventilation support or oxygen exposure [1]. The morbidity costs of this disease include a more than $30 \%$ increase in the number of extra low birth-weight infants born each year in the USA, with mortality as high as $10 \sim 25 \%[2,3]$. Despite advances in the prevention and therapy of respiratory distress syndrome in premature infants, BPD remains a major disease, with many infants experiencing significant recurrent respiratory tract infections and airway hyperresponsiveness throughout childhood $[4,5]$. During normal lung development and differentiation, epithelial and mesenchymal cells ordinarily proliferate and interact. The interruption of such processes may impact lung structure and function and cause disastrous consequences [6].
The main pathological features of BPD are simplified enlarged alveoli, capillary dysplasia, and pulmonary interstitial fibrosis [7]. Although most studies have focused on alveolar epithelial cells in BPD, lung fibroblasts (LFs) also participate in normal lung development and respond to lung injury. Alveolar development and repair are affected by the neighboring pulmonary interstitial fibroblasts, which, in turn, affect extracellular matrix (ECM) remodeling and can cause fibrosis [8]. The main manifestation of pulmonary interstitial fibrosis is the uncontrolled growth of lung fibroblasts that are deposited in the pulmonary interstitium or displaced normal lung epithelium [9].

Pulmonary mesenchymal and epithelial cells interact during localized branching, growth, and extension of primordial tubules. Disruption of this process in premature infants exposed to hyperoxia contributes to BPD [10]. The pathological characteristics of BPD include an uneven proliferation of 
mesenchymal LFs [8]. The regulation of lung fibroblast proliferation is, thus, of clinical and developmental interest.

The extracellular signal-regulated kinase (ERK) cascade plays a vital role in cellular proliferation, especially in tumorigenesis [11]. We have previously found that hyperoxia promoted ERK1/2 phosphorylation and the proliferation of lung fibroblasts rats in vitro [12]. However, the relationship between ERK1/2 and lung fibroblasts is not clear. Fibroblasts act as secretory cells in the lung tissue and mediate normal and pathological remodeling during pulmonary development. However, to date, the role of ERK signaling in cultured primary LFs has been poorly studied. Consequently, in this study, we evaluated mechanisms of cell proliferation, transdifferentiation, and migration of cultured primary lung fibroblasts treated with the ERK activator, epidermal growth factor (EGF), in the presence or absence of the inhibitor, PD98059. Our particular focus was on the impact of activating $\mathrm{p}$-ERK1/2 on proliferation, transdifferentiation, and migration of lung fibroblasts, and the molecular mechanism(s) by which activation of ERK1/2 modulates the progression of BPD.

\section{Materials and Methods}

2.1. Culturing and Treatment of Primary Lung Fibroblasts. The study was approved by the institutional research ethics committee of China Medical University. Newborn rat pups on day 3 of the saccular stage $(n=30)$ were euthanized with an intraperitoneal injection of sodium pentobarbital $(100 \mathrm{mg} / \mathrm{kg})$ prior to removing the lung tissue. When the heart stopped beating and the pupils became dilated, the lung tissue was removed under sterile conditions, finely minced, and digested with $0.25 \%$ trypsin (Santa Cruz Biotechnology, Santa Cruz, CA, USA) in a shaking water bath for $30 \mathrm{~min}$ at $37^{\circ} \mathrm{C}$. Cells were collected and cultured in Dulbecco's modified Eagle's medium (DMEM; Thermo Scientific HyClone, Beijing, China) with 10\% fetal bovine serum (FBS; Thermo Scientific HyClone, Logan, UT, USA). LFs were used in experimental procedures when they became confluent, and showed a typical elongated and spindle-shaped appearance. LFs were identified by vimentin (sc-5565, 1 :100; Santa Cruz Biotechnology, Santa Cruz, CA, USA) staining as we have published previously [13].

LFs were randomly divided into four groups: (1) untreated control; (2) EGF group, which was treated with $20 \mathrm{ng} / \mathrm{mL}$ EGF (Peprotech, Rocky Hill, NJ, USA); (3) PD98059 group, which was treated with $10 \mu \mathrm{mol} / \mathrm{L}$ PD98059 (Cell Signaling Technology, Boston, MA, USA); and (4) EGF+PD98059 group, which was treated with $20 \mathrm{ng} / \mathrm{mL}$ EGF and $10 \mu \mathrm{mol} / \mathrm{L}$ of the ERK inhibitor, PD98059. LFs were collected following a 24-h treatment.

2.2. Immunocytochemistry. LFs were fixed in paraformaldehyde. The proteins, p-ERK1/2 and $\alpha$-smooth muscle actin ( $\alpha$-SMA), were detected using standard streptavidin-peroxidase immunocytochemical staining procedures. Cells were incubated with primary antibody (\#4370 for p-ERK1/2 and \#56856 for $\alpha$-SMA, both 1:100; Cell Signaling Technology, Boston, MA, USA) at $4^{\circ} \mathrm{C}$ overnight. The same procedure without the primary antibody was used as an isotype control. Cells were incubated with secondary antibody (SP-9000; Beijing Zhongshan Goldenbridge Biotechnology, Beijing, China) for $20 \mathrm{~min}$ at $37^{\circ} \mathrm{C}$, followed by horseradish peroxidase (HRP-) labeled streptavidin at $37^{\circ} \mathrm{C}$ for $20 \mathrm{~min}$. Cells were washed with PBS three times between steps. After diaminobenzidine (DAB) staining, LFs were observed using a MetaMorph Imaging System (Universal Imaging Corporation, West Chester, PA, USA). The optical density value was semiquantitatively measured using the MetaMorph software. Five randomly selected high-power fields (400x magnification) were photographed for each slide.

2.3. Western blotting of ERK, $p$-ERK, Type I collagen, and $\alpha-S M A$ in LFs. Total protein was extracted from LFs, quantified, separated by SDS-polyacrylamide gel electrophoresis, and then transferred to nitrocellulose membranes. Membranes were blocked for $1 \mathrm{~h}$ with $5 \%$ nonfat milk followed by incubation with anti-p-ERK1/2, anti-ERK, antitype $I$ collagen (Col- $I$ ), or anti- $\alpha$-SMA primary antibody (\#4370 for p-ERK1/2, \#4696 for ERK1/2, \#91144S for Col- $I$, \#56856 for $\alpha$-SMA; all 1:1000; Cell Signaling Technology, Boston, MA, USA) overnight at $4^{\circ} \mathrm{C}$, and then with HRPlabeled secondary antibody (ZB2305, 1 :2000; Beijing Zhongshan Goldenbridge Biotechnology, Beijing, China) at $37^{\circ} \mathrm{C}$ for $2 \mathrm{~h}$. The blots were developed using electrochemiluminescence after washing three times with Tris-buffered saline containing Tween 20. Films were digitized, and relative grayscale values were calculated. The higher the relative grayscale value, the higher the protein level.

2.4. Cell-Cycle Analysis by Flow Cytometry. To arrest cells in the G0 phase in the cell cycle, LFs were cultured for $24 \mathrm{~h}$ in serum-free DMEM, divided into four treatment groups, and then cultured in DMEM with 10\% FBS for $24 \mathrm{~h}$. LFs were harvested, suspended $\left(1 \times 10^{6}\right.$ cells $\left./ \mathrm{mL}\right)$, then fixed in $75 \%$ cold ethanol at $4^{\circ} \mathrm{C}$. The LFs were treated with $50 \mu \mathrm{g} / \mathrm{mL}$ RNase (Sigma, St. Louis, MO, USA) at $37^{\circ} \mathrm{C}$ for $30 \mathrm{~min}$ then stained with $100 \mu \mathrm{g} / \mathrm{mL}$ propidium iodide (Sigma) at $4^{\circ} \mathrm{C}$ for $30 \mathrm{~min}$ in the dark. The distribution of the cell cycle was evaluated by flow cytometry (Becton, Dickinson and Company, Franklin Lakes, NJ, USA).

2.5. CCK-8 Colorimetric Assay. LFs were cultured for $24 \mathrm{~h}$ in serum-free DMEM and then divided into the four treatment groups in 24 -well plates $\left(5 \times 10^{5}\right.$ cells/ $100 \mu \mathrm{L} /$ well $)$. LFs were incubated for 6,12 , or $24 \mathrm{~h}$ with EGF, PD98059, or EGF+ PD98059 at $37^{\circ} \mathrm{C}$. Cell counting kit-8 (CCK-8; \#C0038; Beyotime, Shanghai, China) was added to each well (10 $\mu \mathrm{L} /$ well) for the final $1 \mathrm{~h}$. The absorbance was calculated at $450 \mathrm{~nm}$ by enzyme-linked immunosorbent assay reader (Shimadzu UV-260, Kyoto, Japan).

2.6. Real-Time Reverse Transcription Quantitative PCR. Quantitative changes in ERK1, ERK2, and $\alpha$-SMA expression were determined by real-time reverse transcriptionquantitative $(\mathrm{RT}-\mathrm{q}) \mathrm{PCR}$. TRizol reagent (Takara, Shiga, Japan) was used to extract total RNA. Aliquots $(500 \mathrm{ng} / \mu \mathrm{L})$ were reverse transcribed to cDNA for $15 \mathrm{~min}$ at $37^{\circ} \mathrm{C}$ and then $5 \mathrm{sec}$ at $85^{\circ} \mathrm{C}$ with a PrimeScript RT Reagent Kit 
TABLE 1: Primers employed for RT-qPCR.

\begin{tabular}{|c|c|c|}
\hline Gene & Sequence & Product size \\
\hline ERK1 & $\begin{array}{l}\text { Sense } 5^{\prime} \text {-GGTAGACGGTTCTGGAATGGAAGG-3' } \\
\text { Antisense 5'-GTCAGGGAAAATGGGGTGGG-3' }\end{array}$ & $128 \mathrm{bp}$ \\
\hline ERK2 & $\begin{array}{c}\text { Sense } 5^{\prime} \text {-TGTTCCCAAACGCTGACTCCA-3' } \\
\text { Antisense } 5^{\prime} \text {-AGTCGTCCAGCTCCATGTCAAACT-3' }\end{array}$ & $180 \mathrm{bp}$ \\
\hline$\alpha-S M A$ & $\begin{array}{l}\text { Sense } 5^{\prime} \text {-AGCCAGTCGCCATCAGGAAC-3' } \\
\text { Antisense } 5^{\prime} \text {-CCGGAGCCATTGTCACACAC-3' }\end{array}$ & $90 \mathrm{bp}$ \\
\hline GAPDH & $\begin{array}{c}\text { Sense } 5^{\prime} \text {-GCACCGTCAAGGCTGAGAAC-3' } \\
\text { Antisense } 5^{\prime} \text {-ATGGTGGTGAAGACGCCAGT-3' }\end{array}$ & $142 \mathrm{bp}$ \\
\hline
\end{tabular}

Notes: ERK: extracellular signal-regulated kinase; GAPDH: glyceraldehyde 3-phosphate dehydrogenase; RT-qPCR: real-time reverse transcriptase quantitative PCR.

(DRR037S; Takara Biotechnology, Dalian, China). Real-time reverse transcription-quantitative $\mathrm{PCR}$ assay conditions were 40 cycles for $10 \mathrm{sec}$ at $95^{\circ} \mathrm{C}, 40$ cycles for $5 \mathrm{sec}$ at $95^{\circ} \mathrm{C}$, followed by $20 \mathrm{sec}$ at $60^{\circ} \mathrm{C}$ using $\mathrm{SYBR}^{\mathrm{R}}$ Premix Ex Taq ${ }^{\mathrm{TM}}$ (DRR041S; Takara Biotechnology, Dalian, China) and a LightCycler 2.0 RT-qPCR System (Roche Diagnostics, Indianapolis, IN, USA). Gene-specific primers were designed and synthesized by Takara. Specific primers were used to detect ERK1, ERK2, $\alpha$-SMA, and GAPDH (Table 1). For each sample, a $\Delta \mathrm{Ct}$ value was obtained.

2.7. Cell Migration Assay. Cellular migration is necessary for the extracellular matrix process. To quantify cell movement, a simple chamber setup was utilized to assess migration in response to different treatment stimuli. A simple Boyden chamber is made up of an outer wall consisting of plate wells and a transwell insert $(8 \mu \mathrm{m}$ pore diameter $)$ placed within each well. LFs $\left(1 \times 10^{5} / 100 \mu \mathrm{L} /\right.$ well $)$ were cultured in the top chamber (Transwell) with $600 \mu \mathrm{L}$ culture solution in the bottom reservoir. LFs were then incubated with EGF, PD98059, or EGF+PD98059 at $37^{\circ} \mathrm{C}$ for $24 \mathrm{~h}$. The control group was untreated. After the treatment, each membrane was washed with PBS three times and fixed with $4 \%$ paraformaldehyde for $30 \mathrm{~min}$. Cells were stained for $15 \mathrm{~min}$ using trypan blue and counted.

2.8. Statistical Analysis. All experiments were repeated five times. The results are expressed as mean \pm standard error (SE). Data were analyzed with ANOVA followed by Student-Newman-Keuls test for multiple comparisons among groups. $P<0.05$ was considered statistically significant.

\section{Results}

3.1. Exposure to EGF Leads to ERK Activation. To evaluate pathologic changes in response to EGF, the expression of p-ERK1/2 was examined by immunocytochemistry and western blotting. The immunocytochemical staining of primary LFs demonstrated $\mathrm{p}$-ERK $1 / 2$ in the nucleus and cytoplasm (Figure 1(a)). The levels of p-ERK1/2 were significantly higher in the EGF group than those in the control group $(P<0.01)$. PD98059 decreased ERK phosphorylation in LFs $(P<0.01)$. The expression of $\mathrm{p}$-ERK1/2 was decreased in the EGF+
PD98059 group compared with that in the EGF group $(P<0.01$; Figure 1(b)).

Equivalent amounts of cellular proteins in LFs were probed by western blot analysis using a specific p-ERK1/2 antibody. As shown in Figures 1(c) and 1(d), a significant increase in p-ERK1/2 levels in LFs exposed to EGF compared to the control group was observed $(P<0.01)$, which decreased when LFs were cotreated with EGF and PD98059 $(P<0.05)$. PD98059 alone also affected the phosphorylation of ERK1/2 $(P<0.05)$. None of the treatments changed the level of nonphosphorylated ERK1/2 $(P>0.05)$.

Real-time reverse transcription-quantitative PCR also revealed no difference in mRNA levels of ERK1 and ERK2 in each group as listed in Table 2 (all $P>0.05$ ).

3.2. Activation of ERK Induces Proliferation of Lung Fibroblasts. The effect of p-ERK1/2 on the proliferation of LFs was investigated by cell-cycle distribution. For the control group, the greatest proportion of cells existed in the G1 phase (Figure 2). Markedly decreased G1-phase and increased S-phase cell populations appeared after EGF treatment for $24 \mathrm{~h}(P<0.01)$, indicating that LFs were not arrested at the G1 checkpoint. In contrast, PD98059 significantly increased the G1 phase $(P<0.01)$ and decreased the S-phase cell population $(P<0.05)$. The progression of S-phase cells cotreated with PD98059 and EGF was also significantly slower than that of cells treated only with EGF $(P<0.05)$. These results were in accordance with the p-ERK level, which indicated that activated ERK is essential for cells to enter the $S$ phase.

A CCK-8 assay revealed that the PD98059 treatment significantly inhibited cell proliferation starting at $12 \mathrm{~h}$, with a peak after $24 \mathrm{~h}(P<0.05)$. A significant difference between the untreated control and the PD98059 groups for cell proliferation after 12 and $24 \mathrm{~h}$ under basal conditions was not noted. The number of LF cells was 1.14-fold higher following the EGF stimulation for $24 \mathrm{~h}$ compared to the untreated control group $(P<0.05)$. Cotreatment with PD98059 and EGF resulted in a decrease after 6,12 , and $24 \mathrm{~h}$ in the number of LFs by $3.6 \%(P>0.05), 15.2 \%(P<0.05)$, and $19.5 \%$ $(P<0.01)$, respectively, compared to the control group (Figure 3). 


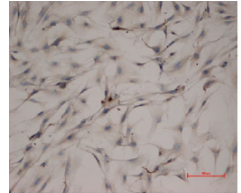

Control

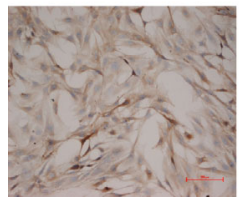

EGF

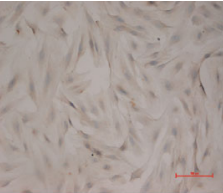

PD98059

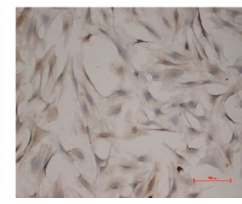

$\mathrm{EGF}+\mathrm{PD} 98059$

(a)

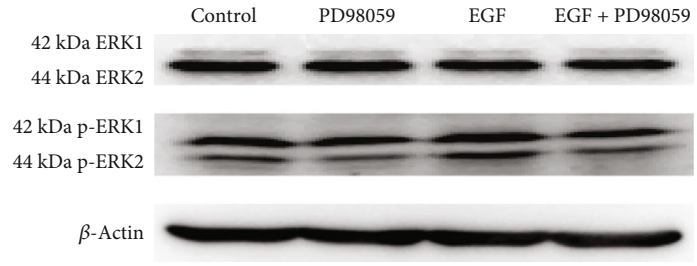

(c)

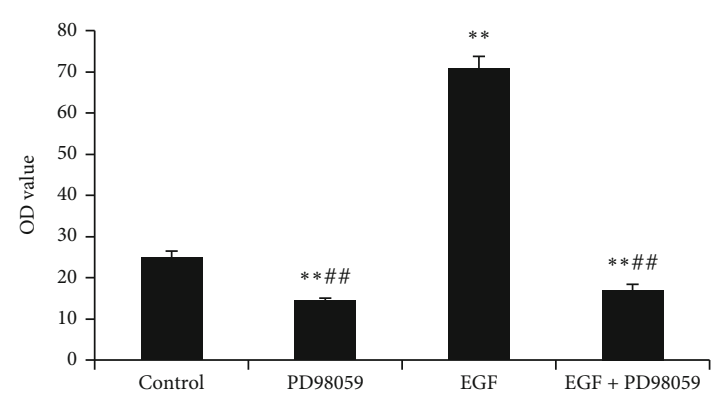

(b)

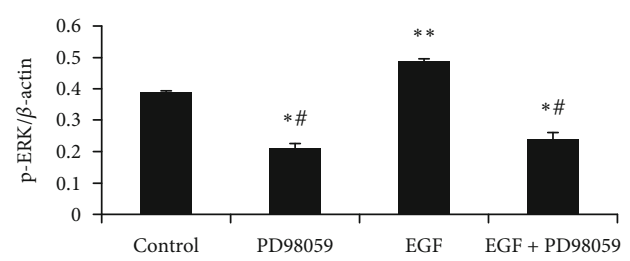

(d)

FIGURE 1: $(a, b)$ Protein expression level of p-ERK was detected by immunocytochemistry in the lung fibroblasts (LFs) following treatment $($ scale bar $=100 \mu \mathrm{m})$. Positive phosphorylated extracellular signal-regulated kinase (p-ERK)1/2 antigen expression was found distributed in the cell cytoplasm and nucleus. (c, d). ERK and p-ERK protein levels in LFs following treatment were detected in the western blots of protein samples from the four groups. Control group: LFs without any treatment; PD98059 group: LFs treated with 10 $\mu \mathrm{mol} / \mathrm{L}$ PD98059; epidermal growth factor (EGF) group: LFs treated with $20 \mathrm{ng} / \mathrm{mL}$ EGF; EGF+PD98059 group: LFs treated with both $20 \mathrm{ng} / \mathrm{mL}$ EGF and $10 \mu \mathrm{mol} / \mathrm{L}$ PD98059. All treatments were administered for $24 \mathrm{~h}$. Data are presented as the mean $\pm \operatorname{standard~deviation~}(\mathrm{SD} ; n=5)$. ${ }^{*} P<0.05$ vs. control cells. ${ }^{* *} P<0.01$ vs. control cells. ${ }^{\#} P<0.05$ vs. EGF group. ${ }^{\# \#} P<0.01$ vs. EGF group.

TABLE 2: The relative mRNA level of ERK1/2 in LFs $(\bar{X} \pm s, n=5)$.

\begin{tabular}{lcccc}
\hline$\triangle$ Ct/group & Control & PD98059 & EGF & EGF+PD98059 \\
\hline ERK1 & $5.16 \pm 0.41$ & $5.34 \pm 0.36$ & $5.49 \pm 0.43$ & $5.48 \pm 0.35$ \\
ERK2 & $4.44 \pm 0.34$ & $4.50 \pm 0.38$ & $4.38 \pm 0.24$ & $4.36 \pm 0.28$ \\
\hline
\end{tabular}

Notes: EGF: epidermal growth factor; ERK: extracellular signal-regulated kinase ${ }^{*} P<0.05$ vs. control cells, ${ }^{* *} P<0.01$ vs. control cells.

Col-I protein was assayed by western blotting. EGF promoted the production of Col-I protein $(P<0.01)$; PD98059 significantly inhibited the effect of EGF $(P<0.01)$ compared with the controls (Figures 4(a) and 4(b)).

3.3. Activation of ERK Promotes Transdifferentiation of Lung Fibroblasts. As shown in Figures 5(a) and 5(b), immunocytochemical staining and western blotting of primary LF cultures demonstrated that the $\alpha$-SMA protein expression was significantly increased in the EGF group compared with the control group $(P<0.01)$. This effect was inhibited by PD98059 $(P<0.01)$.

As shown in Table 3, RT-qPCR revealed that the $\alpha$-SMA expression in the EGF group was 2.85-fold higher compared to that in the untreated control group $(P<0.01)$. The expression of $\alpha$-SMA mRNA in the EGF group was significantly inhibited by PD98059 $(P<0.01)$. PD98059 alone also decreased the expression of the $\alpha$-SMA mRNA level compared to the control group $(P<0.01)$.

3.4. Activation of ERK Promotes Migration of Lung Fibroblasts. As shown in Figure 6, transwell migration assays revealed that EGF significantly promoted the migration of LFs $(P<0.01)$. Moreover, the expression of $\mathrm{p}-\mathrm{ERK} 1 / 2$ was promoted by EGF in LFs. Primary cultured LFs were treated with both EGF and PD98059 for $24 \mathrm{~h}$. The effect of EGF on the LF migration was inhibited by PD98059 $(P<0.01)$.

\section{Discussion}

A newborn's immature pulmonary response to pulmonary surfactants, assisted ventilation, and oxygen supplementation is characterized by a serious injury to alveoli, interstitial tissues, and pulmonary vasculature. This results in tissue remodeling, developmental disorders, and interstitial fibrosis that may ultimately lead to the development of BPD $[14,15]$. This pathology is clearly observed in the immature lung cells of newborn rats that develop BPD [16]. Using hematoxylineosin staining and immunohistochemistry methods, we have found that the immature lungs exposed to long-term hyperoxia result in fibrogenesis and a significantly higher expression of $\mathrm{p}$-ERK protein in both lung tissue and primary cultured fibroblasts of newborn Wistar rats [12]. In this study, 


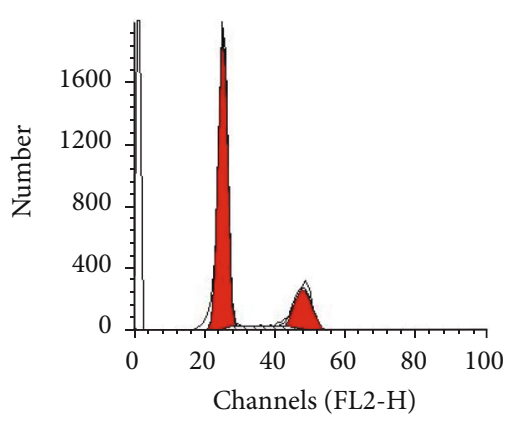

Control

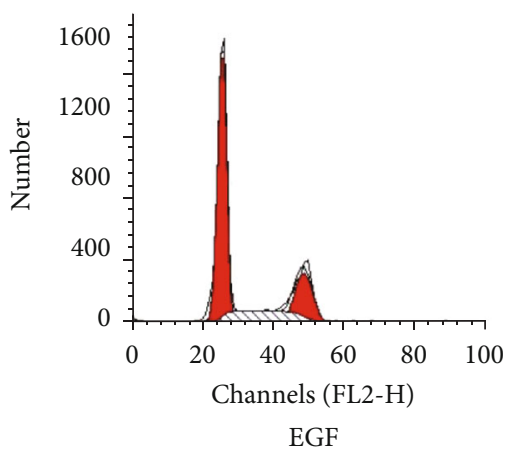

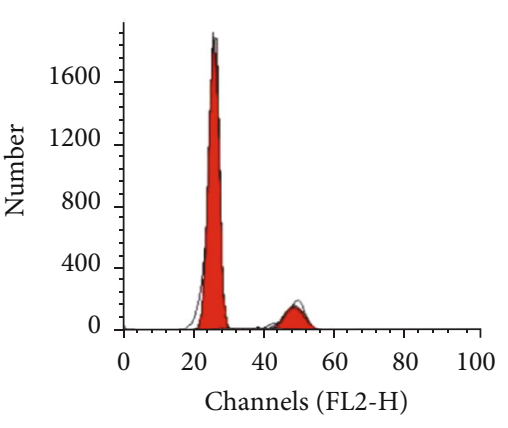

PD98059

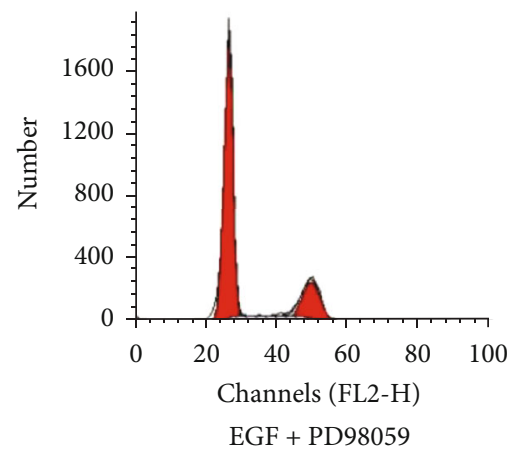

(a)

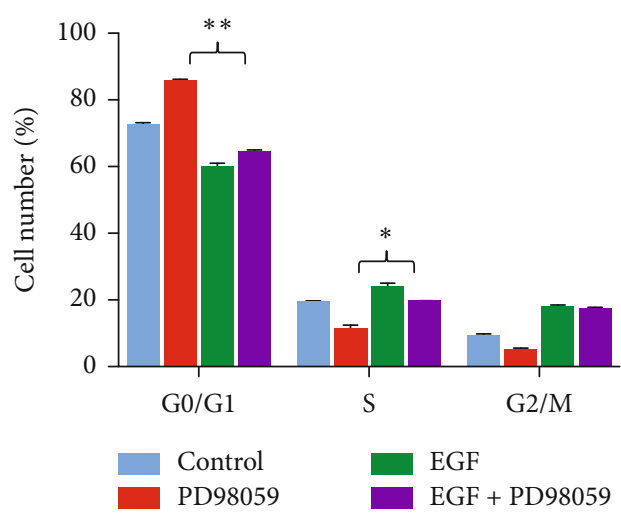

(b)

Figure 2: Cell cycle distribution. Cell populations at G0/G1, S, and G2/M phases were determined by averaging the results from five independent experiments. Control group: lung fibroblasts (LFs) without any treatment; PD98059 group: LFs treated with $10 \mu \mathrm{mol} / \mathrm{L}$ PD98059; epidermal growth factor (EGF) group: LFs treated with $20 \mathrm{ng} / \mathrm{mL}$ EGF; EGF+PD98059 group: LFs treated with both $20 \mathrm{ng} / \mathrm{mL}$ EGF and $10 \mu \mathrm{mol} / \mathrm{L}$ PD98059. All treatments were administered for $24 \mathrm{~h} .{ }^{*} P<0.05,{ }^{* *} P<0.01 \mathrm{vs}$. control cells.

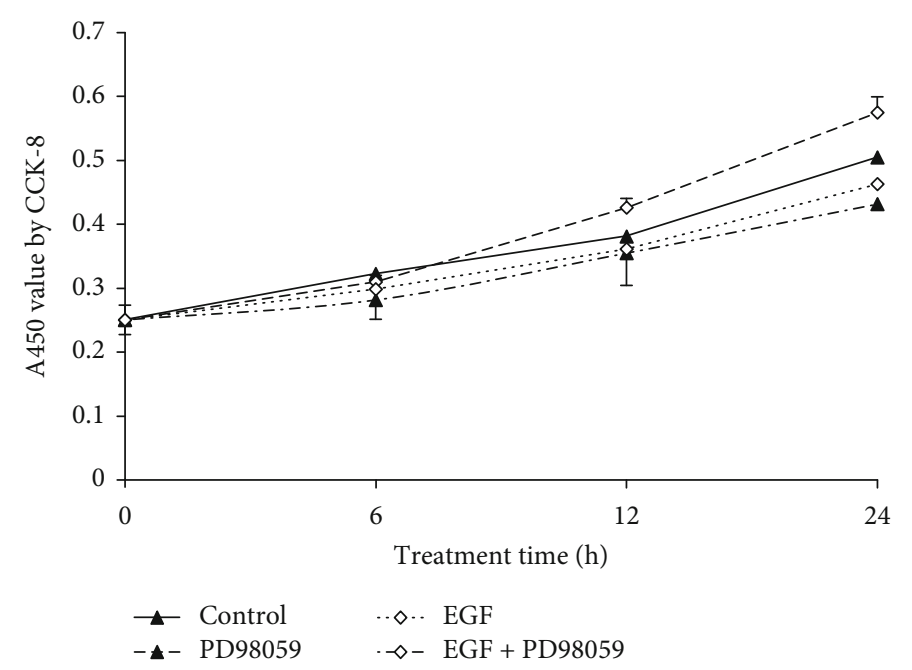

FIGURE 3: Effect of treatments on LF cell proliferation. The CCK-8 assay was used to measure lung fibroblast (LF) proliferation. Epidermal growth factor $(\mathrm{EGF})$ alone $(20 \mathrm{ng} / \mathrm{mL})$ promoted cell proliferation after $24 \mathrm{~h}$ under basal conditions $(P<0.05)$. PD98059 treatment significantly inhibited LF cell proliferation from 12 to 24 h (both $P<0.05$ ). The coincubation of PD98059 and EGF inhibited the activity of EGF alone in cell proliferation after $12 \mathrm{~h}(P<0.05)$ and $24 \mathrm{~h}(P<0.01)$.

fibroblasts isolated from newborn rat lungs proliferated and migrated following the p-ERK activation after the EGF treatment. This suggests that the activation of ERK1/2 is closely linked to the proliferation, transdifferentiation, and migration of LFs and may play an important role in disturbing the repair or remodeling of pulmonary epithelial cells, giving rise to
BPD. Our results were consistent with the pathological changes observed in BPD characterized by interstitial fibrosis.

In the ECM, LFs play essential roles in the response to the pulmonary epithelial injury and interstitial fibrosis in BPD. Several research groups have investigated the effects of the exposure of LFs to hyperoxia, but the results were inconsistent. Lang et al. 


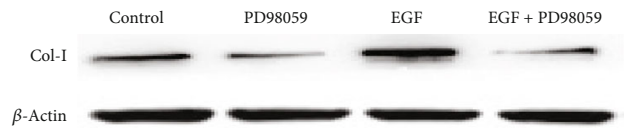

(a)

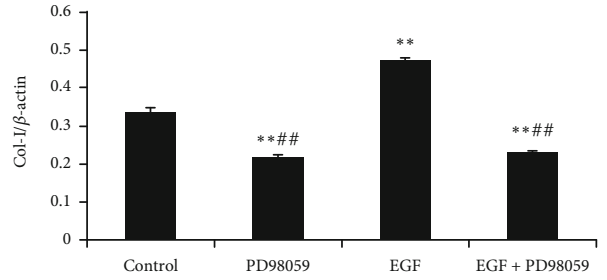

(b)

FIGURE 4: Col-I protein levels in lung fibroblasts following treatment were detected by western blotting. Control group: lung fibroblasts (LFs) without any treatment; PD98059 group: lung fibroblasts (LFs) treated with $10 \mu \mathrm{mol} / \mathrm{L}$ PD98059; epidermal growth factor (EGF) group: LFs treated with $20 \mathrm{ng} / \mathrm{mL}$ EGF; EGF+PD98059 group: LFs treated with both $20 \mathrm{ng} / \mathrm{mL}$ EGF and $10 \mu \mathrm{mol} / \mathrm{L}$ PD98059. All treatments were administered for $24 \mathrm{~h}$. Data are presented as the mean \pm standard deviation $(\mathrm{SD} ; n=5) .{ }^{* *} P<0.01$ vs. control cells. ${ }^{\# \#} P<0.01$ vs. EGF group.

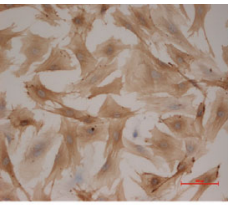

Control

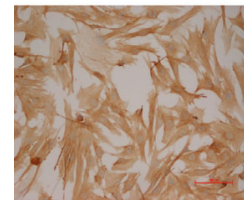

EGF

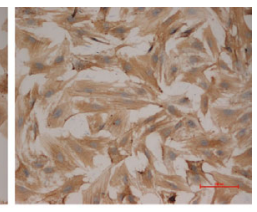

PD98059

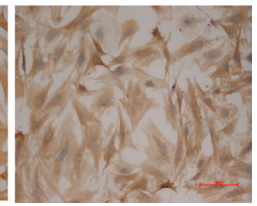

$\mathrm{EGF}+\mathrm{PD} 98059$

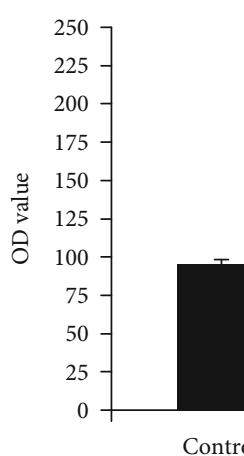

Control

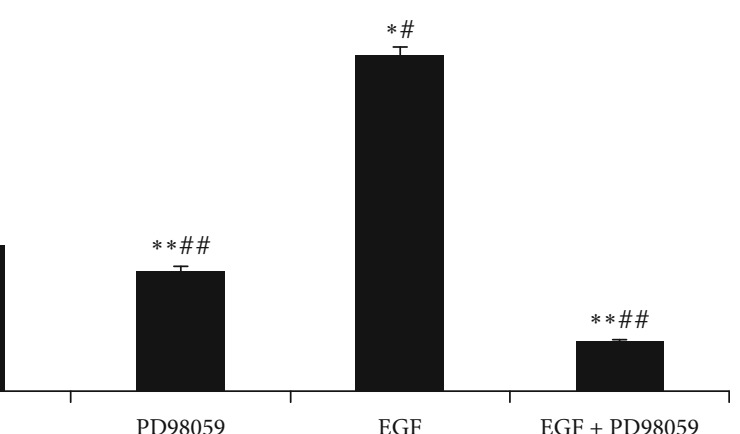

(b) (a)

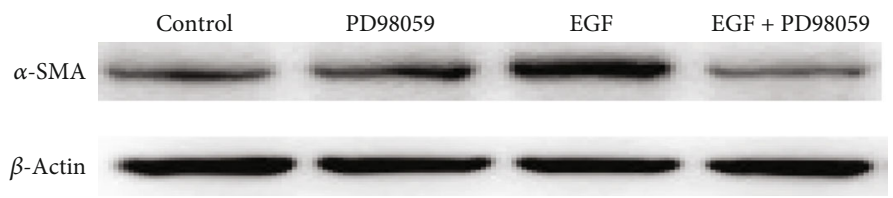

(c)

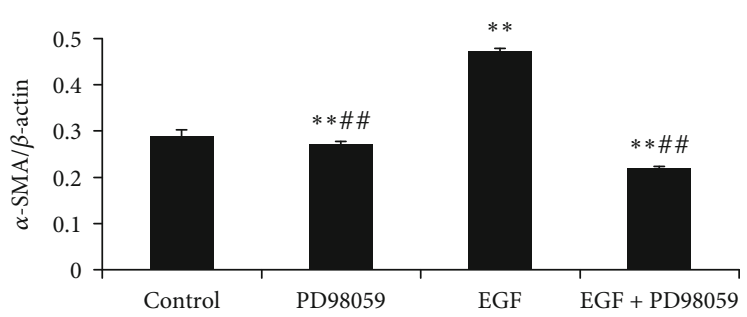

(d)

FIGURE 5: Effect of treatments on alpha smooth muscle actin ( $\alpha$-SMA) protein expression. (a, b) $\alpha$-SMA protein expression by immunocytochemical staining and analysis of protein level. (c, d) $\alpha$-SMA protein levels in lung fibroblasts (LFs) following the treatment were detected by western blotting. Control group: LFs without any treatment; PD98059 group: LFs treated with $10 \mu \mathrm{mol} / \mathrm{L}$ PD98059; epidermal growth factor (EGF) group: LFs treated with $20 \mathrm{ng} / \mathrm{mL}$ EGF; EGF+PD98059 group: LFs treated with both $20 \mathrm{ng} / \mathrm{mL}$ EGF and $10 \mu \mathrm{mol} / \mathrm{L}$ PD98059. All treatments were administered for $24 \mathrm{~h}$. Data are presented as the mean \pm standard deviation $(\mathrm{SD} ; n=5) .{ }^{*} P<0.05$ vs. control cells. ${ }^{* *} P<0.01$ vs. control cells. ${ }^{\# \#} P<0.01$ vs. EGF group. Scale bar $=100 \mu \mathrm{m}$.

TABLE 3: The relative mRNA level of $\alpha$-SMA in LFs $(\bar{X} \pm s, n=5)$.

\begin{tabular}{lcccc}
\hline Group & Control & PD98059 & EGF & EGF+PD98059 \\
\hline$\triangle$ Ct value & $-1.05 \pm 0.29$ & $0.72 \pm 0.17^{* *}$ & $-2.56 \pm 0.18^{* *}$ & $-0.08 \pm 0.16^{* *}$ \\
\hline
\end{tabular}

Notes: LF: lung fibroblasts; $\alpha$-SMA: $\alpha$-smooth muscle actin. ${ }^{* *} P<0.01$ vs. control cells.

demonstrated an increased p-ERK1/2, Col-I, and $\alpha$-SMA expression when human fetal LFs were exposed to 95\% hyperoxia for $12 \mathrm{~h}$ to $48 \mathrm{~h}$ [17]. However, two other studies showed conflicting results for primary cultures of fibroblasts obtained from mature adult lungs or in the exposure of cultured fetal rat lung fibroblasts to elevated levels of $\mathrm{O}_{2}$, including the inhibition of fibroblast proliferation $[18,19]$. Differences in the results obtained may be due to differences in the experimental conditions used and/or observation times. EGF is a soluble factor important for lung development that is active during the 


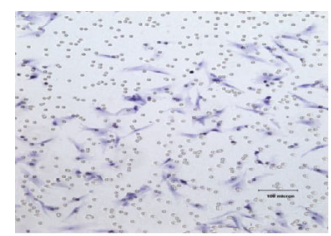

Control

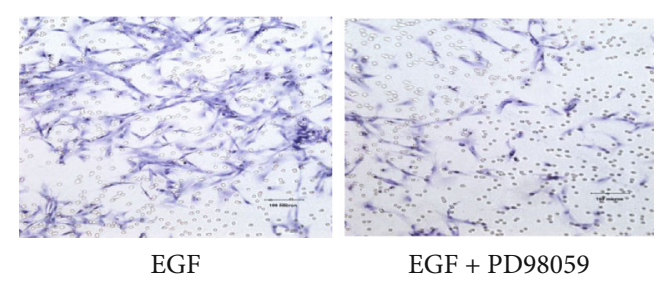

(a)

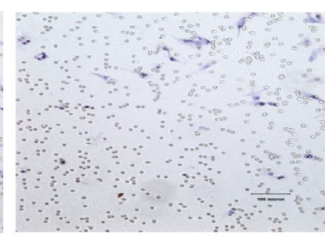

PD98059

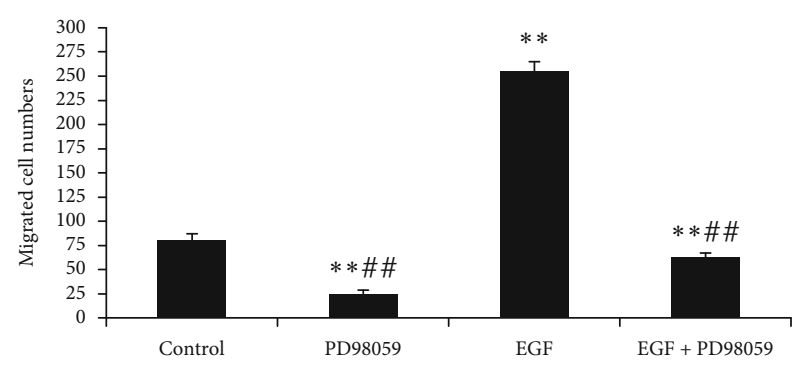

(b)

Figure 6: Effects of treatment on the migration of lung fibroblasts using the transwell method. Control group: lung fibroblasts (LFs) without any treatment; PD98059 group: LFs treated with $10 \mu \mathrm{mol} / \mathrm{L}$ PD98059; epidermal growth factor (EGF) group: LFs treated with $20 \mathrm{ng} / \mathrm{mL}$ EGF; EGF+PD98059 group: LFs treated with both $20 \mathrm{ng} / \mathrm{mL}$ EGF and $10 \mu \mathrm{mol} / \mathrm{L}$ PD98059. All treatments were administered for $24 \mathrm{~h} .{ }^{* *} P<0.01$ vs. control cells. ${ }^{\# \#} P<0.01$ vs. EGF group. Scale bar $=100 \mu \mathrm{m}$.

epithelial-mesenchymal crosstalk [20]. It acts via the ERK pathway [21-23]. We therefore used EGF to stimulate the activated ERK and found a role for the ERK signaling pathway in regulating LF proliferation.

Hyperoxia activates ERK in neonatal rats on postnatal days 7 and 21 and promotes alveolar interstitial fibroblast transdifferentiation into myofibroblasts $[24,25]$. Indeed, the activation of the ERK pathway has been previously demonstrated in lung epithelial cells exposed to hyperoxia, which prolonged cell survival and protected cells from hyperoxia-induced death [26]. Bleomycin and high tidal volume ventilation-induced lung fibrosis depended, in part, on the activation of ERK1/2 pathways. This effect was abrogated by the ERK1/2 inhibitor, PD98059, in mice treated with high tidal volume ventilation [27]. However, the relationship between ERK phosphorylation and BPD development requires further investigation. The present study demonstrated that the stimulation with EGF activated the ERK signaling pathway. This suggests that the underlying molecular mechanisms may involve activated ERK in LFs inducing proliferative and migratory signals.

In addition, the mechanisms by which the ERK pathway acts in BPD may be due to how it participates in normal lung development. The Mek gene was recently shown to encode mitogen-activated protein kinase (MAPK), which phosphorylates and activates ERK. A certain amount of $M e k$ gene was indispensable to normal placenta development and embryo survival [28]. The Mek gene has two homologs: Mek1 and Mek2. Loss of the Mek1 gene resulted in embryo defects and death while the Mek2 gene was not necessary because of the compensatory function of the Mekl gene [29]. The knockdown of both Mek genes in lung epithelial cells resulted in lung hypoplasia and even death. A deficiency of Mek genes impaired lung development and caused branching defects in cultured whole-lung embryo explants. The mechanisms involved may be decreased respiratory epithelial cell proliferation coupled with increased cell death [30]. Mek gene inactivation in the lung mesenchyme caused lung hypoplasia and tracheal defects because of increased apoptosis and reduced branching. Moreover, it indicated that ERK potentially interacts with the Wnt pathway during lung development [31]. The appearance of pulmonary dysplasia is characterized by reduced branching, increased apoptosis, and decreased mesenchymal cell proliferation.

ERK may also promote fibrosis through transduction signaling by transforming growth factor (TGF) $\beta$ and matrix metalloproteinases (MMPs). TGF- $\beta 1$ induces collagen production and $\alpha$-SMA expression in human LFs by promoting ERK1/2 activation [32]. The stimulation of TGF- $\beta$ increased MMP and p-ERK1/2 expression in primary cultured human LFs [33]. As a sulfated oligosaccharide that is extracted from seaweed, MS80 arrested the proliferation of human embryonic LFs, MMP activity, and collagen deposition stimulated by TGF- $\beta 1$, and ultimately inhibited bleomycin-induced lung fibrosis in rats [34]. It seems that the formation of fibrosis promoted by MMPs or TGF- $\beta$ is closely related to the activity of ERK1/2. However, direct evidence showing ERK1/2 was upstream or downstream of TGF- $\beta$ or MMP signaling pathways was absent. In vitro, it was demonstrated that both rosiglitazone and hydrogen sulfide suppress migration, proliferation, and the phenotypic differentiation of human LFs by inhibiting ERK activation. The two drugs may be effective in patients with pulmonary fibrosis $[35,36]$. Above all, ERK1/2 may be a target for the prevention and therapy of pulmonary hypoplasia and fibrosis associated with BPD in premature infants.

\section{Conclusions}

The activation of ERK promotes the proliferation, transdifferentiation, and migration of lung fibroblasts in newborn rats. However, further and more detailed studies are required into the exact cellular pathways involved in the ERK activation in BPD. 


\section{Data Availability}

All relevant data are within this manuscript, and all data are fully available without restriction.

\section{Conflicts of Interest}

The authors declare that they have no conflicts of interest.

\section{Acknowledgments}

This work was supported by the Natural Science Foundation of China under Grant [number 30801245].

\section{References}

[1] R. Kalikkot Thekkeveedu, M. C. Guaman, and B. Shivanna, "Bronchopulmonary dysplasia: a review of pathogenesis and pathophysiology," Respiratory Medicine, vol. 132, pp. 170177, 2017.

[2] J. Ma and H. Ye, "Effects of permissive hypercapnia on pulmonary and neurodevelopmental sequelae in extremely low birth weight infants: a meta-analysis," Springerplus, vol. 5, no. 1, p. 764, 2016.

[3] N. Principi, G. M. Di Pietro, and S. Esposito, "Bronchopulmonary dysplasia: clinical aspects and preventive and therapeutic strategies," Journal of Translational Medicine, vol. 16, no. 1, p. 36, 2018.

[4] S. A. McGrath-Morrow, M. Hayashi, A. D. Aherrera, and J. M. Collaco, "Respiratory outcomes of children with BPD and gastrostomy tubes during the first 2 years of life," Pediatric Pulmonology, vol. 49, no. 6, pp. 537-543, 2014.

[5] K. Skromme, M. Vollsæter, K. Øymar, T. Markestad, and T. Halvorsen, "Respiratory morbidity through the first decade of life in a national cohort of children born extremely preterm," BMC Pediatrics, vol. 18, no. 1, p. 102, 2018.

[6] C. L. Day and R. M. Ryan, "Bronchopulmonary dysplasia: new becomes old again!," Pediatric Research, vol. 81, no. 1-2, pp. 210-213, 2017.

[7] J. J. Coalson, "Pathology of bronchopulmonary dysplasia," Seminars in Perinatology, vol. 30, no. 4, pp. 179-184, 2006.

[8] S. McGowan, "Understanding the developmental pathways pulmonary fibroblasts may follow during alveolar regeneration," Cell and Tissue Research, vol. 367, no. 3, pp. 707-719, 2017.

[9] J. T. Allen and M. A. Spiteri, "Growth factors in idiopathic pulmonary fibrosis: relative roles," Respiratory Research, vol. 3, no. 1, p. 13, 2002.

[10] D. Hayes Jr., D. J. Feola, B. S. Murphy, L. A. Shook, and H. O. Ballard, "Pathogenesis of bronchopulmonary dysplasia," Respiration, vol. 79, no. 5, pp. 425-436, 2010.

[11] D. Fey, D. Matallanas, J. Rauch, O. S. Rukhlenko, and B. N. Kholodenko, "The complexities and versatility of the RAS-toERK signalling system in normal and cancer cells," Seminars in Cell \& Developmental Biology, vol. 58, pp. 96-107, 2016.

[12] Y. Hu, J. Fu, and X. Xue, "Association of the proliferation of lung fibroblasts with the ERK1/2 signaling pathway in neonatal rats with hyperoxia-induced lung fibrosis," Experimental and Therapeutic Medicine, vol. 17, no. 1, pp. 701-708, 2019.

[13] X. Wang, J. H. Fu, and X. D. Xue, "Expression dynamics of caveolin-1 in fibroblasts of newborn rats with chronic lung dis- ease and its impact on lung fibroblast proliferation," Acta Cirúrgica Brasileira, vol. 32, no. 5, pp. 359-368, 2017.

[14] S. Perrone, C. Bracciali, N. di Virgilio, and G. Buonocore, "Oxygen use in neonatal care: a two-edged sword," Frontiers in Pediatrics, vol. 4, p. 143, 2017.

[15] E. Cutz and D. Chiasson, "Chronic lung disease after premature birth," The New England Journal of Medicine, vol. 358, no. 7, pp. 743-745, 2008.

[16] S. M. Zhao, H. M. Wu, M. L. Cao, and D. Han, "Primary culture of lung fibroblasts from hyperoxia-exposed rats and a proliferative characteristics study," Cytotechnology, vol. 70, no. 2, pp. 751-760, 2018.

[17] Y. D. Lang, C. L. Hung, T. Y. Wu, L. F. Wang, and C. M. Chen, "The renin-angiotensin system mediates hyperoxia-induced collagen production in human lung fibroblasts," Free Radical Biology \& Medicine, vol. 49, no. 1, pp. 88-95, 2010.

[18] M. D. Kelleher, E. T. Naureckas, J. Solway, and M. B. Hershenson, "In vivo hyperoxic exposure increases cultured lung fibroblast proliferation and c-Ha-ras expression," American Journal of Respiratory Cell and Molecular Biology, vol. 12, no. 1, pp. 19-26, 1995.

[19] N. Hussain, F. Wu, C. Christian, and M. J. Kresch, "Hyperoxia inhibits fetal rat lung fibroblast proliferation and expression of procollagens," The American Journal of Physiology, vol. 273, no. 4, pp. L726-L732, 1997.

[20] B. L. M. Hogan, C. E. Barkauskas, H. A. Chapman et al., "Repair and regeneration of the respiratory system: complexity, plasticity, and mechanisms of lung stem cell function," Cell Stem Cell, vol. 15, no. 2, pp. 123-138, 2014.

[21] J. H. Park and H. J. Han, "Caveolin-1 plays important role in EGF-induced migration and proliferation of mouse embryonic stem cells: involvement of PI3K/Akt and ERK," American Journal of Physiology-Cell Physiology, vol. 297, no. 4, pp. C935-C944, 2009.

[22] C. Frémin, A. Bessard, F. Ezan et al., "Multiple division cycles and long-term survival of hepatocytes are distinctly regulated by extracellular signal-regulated kinases ERK1 and ERK2," Hepatology, vol. 49, no. 3, pp. 930-939, 2009.

[23] M. A. Shatos, J. Gu, R. R. Hodges, K. Lashkari, and D. A. Dartt, "ERK/p44p42 mitogen-activated protein kinase mediates EGF-stimulated proliferation of conjunctival goblet cells in culture," Investigative Ophthalmology \& Visual Science, vol. 49, no. 8, pp. 3351-3359, 2008.

[24] J. S. Jiang, Y. D. Lang, H. C. Chou et al., "Activation of the renin-angiotensin system in hyperoxia-induced lung fibrosis in neonatal rats," Neonatology, vol. 101, no. 1, pp. 47-54, 2012.

[25] Z. Li, R. Choo-Wing, H. Sun et al., "A potential role of the JNK pathway in hyperoxia-induced cell death, myofibroblast transdifferentiation and TGF- $\beta 1$-mediated injury in the developing murine lung," BMC Cell Biology, vol. 12, no. 1, p. 54, 2011.

[26] S. Buckley, B. Driscoll, L. Barsky, K. Weinberg, K. Anderson, and D. Warburton, "ERK activation protects against DNA damage and apoptosis in hyperoxic rat AEC2," The American Journal of Physiology, vol. 277, no. 1, pp. L159-L166, 1999.

[27] L. F. Li, S. K. Liao, C. C. Huang, M. J. Hung, and D. A. Quinn, "Serine/threonine kinase-protein kinase B and extracellular signal-regulated kinase regulate ventilator-induced pulmonary fibrosis after bleomycin-induced acute lung injury: a prospective, controlled animal experiment," Critical Care, vol. 12, no. 4, p. R103, 2008. 
[28] R. Aoidi, A. Maltais, and J. Charron, "Functional redundancy of the kinases MEK1 and MEK2: rescue of theMek1mutant phenotype byMek2knock-in reveals a protein threshold effect," Science Signaling, vol. 9, no. 412, p. ra9, 2016.

[29] L.-F. Bélanger, S. Roy, M. Tremblay et al., "Mek2 is dispensable for mouse growth and development," Molecular and Cellular Biology, vol. 23, no. 14, pp. 4778-4787, 2003.

[30] O. Boucherat, V. Nadeau, F. A. Bérubé-Simard, J. Charron, and L. Jeannotte, "Crucial requirement of ERK/MAPK signaling in respiratory tract development," Development, vol. 142, no. 21, p. 3801, 2015.

[31] O. Boucherat, K. Landry-Truchon, R. Aoidi et al., "Lung development requires an active ERK/MAPK pathway in the lung mesenchyme," Developmental Dynamics, vol. 246, no. 1, pp. 72-82, 2017.

[32] F. Caraci, E. Gili, M. Calafiore et al., "TGF- $\beta 1$ targets the GSK$3 \beta / \beta$-catenin pathway via ERK activation in the transition of human lung fibroblasts into myofibroblasts," Pharmacological Research, vol. 57, no. 4, pp. 274-282, 2008.

[33] K. Asano, Y. Shikama, N. Shoji, K. Hirano, H. Suzaki, and H. Nakajima, "Tiotropium bromide inhibits TGF- $\beta$-induced MMP production from lung fibroblasts by interfering with Smad and MAPK pathways in vitro," International Journal of Chronic Obstructive Pulmonary Disease, vol. 5, pp. 277286, 2010.

[34] H. D. Jiang and H. S. Guan, "MS80, a novel sulfated oligosaccharide, inhibits pulmonary fibrosis by targeting TGF- $\beta 1$ both in vitro and in vivo," Acta Pharmacologica Sinica, vol. 30, no. 7, pp. 973-979, 2009.

[35] L. P. Fang, Q. Lin, C. S. Tang, and X. M. Liu, "Hydrogen sulfide suppresses migration, proliferation and myofibroblast transdifferentiation of human lung fibroblasts," Pulmonary Pharmacology \& Therapeutics, vol. 22, no. 6, pp. 554-561, 2009.

[36] Q. Lin, L. P. Fang, W. W. Zhou, and X. M. Liu, "Rosiglitazone inhibits migration, proliferation, and phenotypic differentiation in cultured human lung fibroblasts," Experimental Lung Research, vol. 36, no. 2, pp. 120-128, 2010. 